\title{
Thermal Barrier Coatings For Low Emission, High Efficiency Diesel Engine Applications
}

\author{
M. B. Beardsley, P. G. Happoldt and K. C. Kelley \\ Caterpillar Inc. \\ E. F. Rejda and D. F. Socie \\ University of Illinois
}

Permission is hereby granted for a copyright release fee of $\$ 300$ per paper. An invoice will follow under separate cover. Please be sure to include the following credit statement with these papers:

"(C) Society of Automotive Engineers, Inc. The following papers are published on this web-site with permission from the Society of Automotive Engineers, Inc. As a user of this web-site, you are permitted to view these papers on-line, download the PDF file and to print a copy at no cost for your use only. Dowloaded PDF files and printouts of SAE papers contained on this web-site may not be copied or distributed to others or for the use of others." 
The appearance of this ISSN code at the bottom of this page indicates SAE's consent that copies of the paper may be made for personal or internal use of specific clients. This consent is given on the condition, however, that the copier pay a $\$ 7.00$ per article copy fee through the Copyright Clearance Center, Inc. Operations Center, 222 Rosewood Drive, Danvers, MA 01923 for copying beyond that permitted by Sections 107 or 108 of the U.S. Copyright Law. This consent does not extend to other kinds of copying such as copying for general distribution, for advertising or promotional purposes, for creating new collective works, or for resale.

SAE routinely stocks printed papers for a period of three years following date of publication. Direct your orders to SAE Customer Sales and Satisfaction Department.

Quantity reprint rates can be obtained from the Customer Sales and Satisfaction Department.

To request permission to reprint a technical paper or permission to use copyrighted SAE publications in other works, contact the SAE Publications Group.

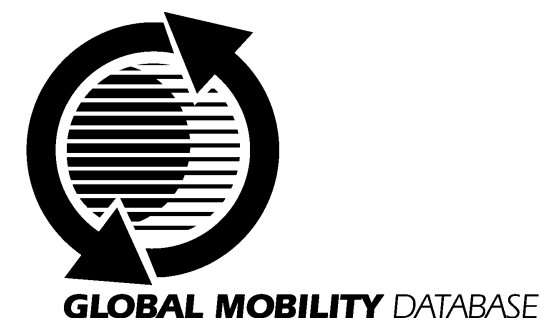

All SAE papers, standards, and selected books are abstracted and indexed in the Global Mobility Database

No part of this publication may be reproduced in any form, in an electronic retrieval system or otherwise, without the prior written permission of the publisher.

\section{ISSN 0148-7191}

Copyright 1999 Society of Automotive Engineers, Inc.

Positions and opinions advanced in this paper are those of the author(s) and not necessarily those of SAE. The author is solely responsible for the content of the paper. A process is available by which discussions will be printed with the paper if it is published in SAE Transactions. For permission to publish this paper in full or in part, contact the SAE Publications Group.

Persons wishing to submit papers to be considered for presentation or publication through SAE should send the manuscript or a 300 word abstract of a proposed manuscript to: Secretary, Engineering Meetings Board, SAE.

\section{Printed in USA}




\title{
Thermal Barrier Coatings For Low Emission, High Efficiency Diesel Engine Applications
}

\author{
M. B. Beardsley, P. G. Happoldt and K. C. Kelley \\ Caterpillar Inc. \\ E. F. Rejda and D. F. Socie \\ University of Illinois
}

Copyright (C) 1999 Society of Automotive Engineers, Inc.

\begin{abstract}
Thermal efficiencies of $54 \%$ have been demonstrated by single cylinder engine testing of advanced diesel engine concepts developed under Department of Energy funding. In order for these concept engines to be commercially viable, cost effective and durable systems for insulating the piston, head, ports and exhaust manifolds will be required. The application and development of new materials such as thick thermal barrier coating systems will be key to insulating these components. Development of test methods to rapidly evaluate the durability of coating systems without expensive engine testing is a major objective of current work. In addition, a novel, low cost method for producing thermal barrier coated pistons without final machining of the coating has been developed.
\end{abstract}

\section{INTRODUCTION}

Prior engine testing has demonstrated the benefit of insulating engine components to achieve lower fuel consumption and lower component temperatures in diesel engines. (Ref. 1 \& 2) Thick thermal barrier coatings (TTBCs), 2 to $3.5 \mathrm{~mm}$ thick, used for these demonstrations have not had the durability desired for production use in advanced diesel engine concepts. Current development efforts of TTBC systems are now concentrating on understanding the material property behavior of the TTBC systems, development of a gas impermeable seal coating, lower cost methods of manufacturing and nondestructive evaluation techniques for use in quality control and development.

\section{TTBC MATERIAL PROPERTY CHARACTERIZATION}

The understanding of strength and cyclic fatigue properties of TTBC systems continues to grow. Methods for testing compressive and tensile strengths developed by Brink (Ref.3) have been expanded to cyclic fatigue testing by Socie, et al. (Ref. 4) Increases in the cyclic fatigue strength at high temperatures, found by Socie, et al., was originally thought to be caused by a sintering phenomenon. Recent work investigating the stress strain response of the TTBC ceramic materials now suggests that the increased fatigue strength is due to the inelastic behavior of the coating. (Ref. 5).

By using tube specimens of the TTBC ceramic materials, test techniques have been developed to investigate the cyclic response of the material. The specimen geometry shown in Figure 1 is produced by spraying the ceramic material onto a composite stainless steel/mild steel substrate followed by machining of the ceramic and acid removal of the mild steel. By using this sample, the ceramic material can be cycled in tension and compression. A typical response of a calcium titanate TTBC ceramic is shown in Figure 2. The sample was loaded in compression to two thirds of its compressive strength and then unloaded back to a tensile stress that caused failure. Note the inelastic strain caused by the compressive loading requires a tensile stress to bring the sample back to a zero strain state.

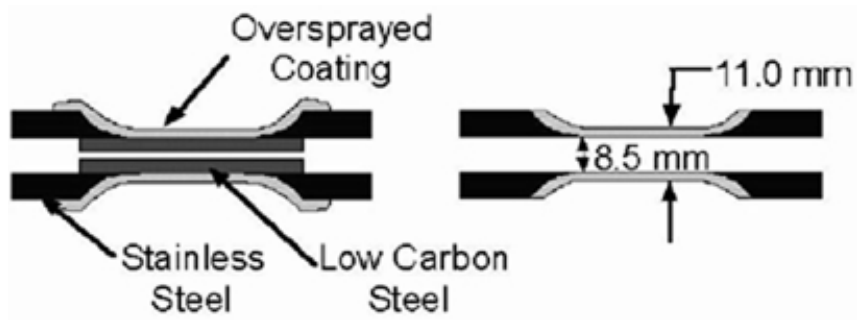

Figure 1. Specimen geometry used for studying the cyclic fatigue response of TTBC materials. 


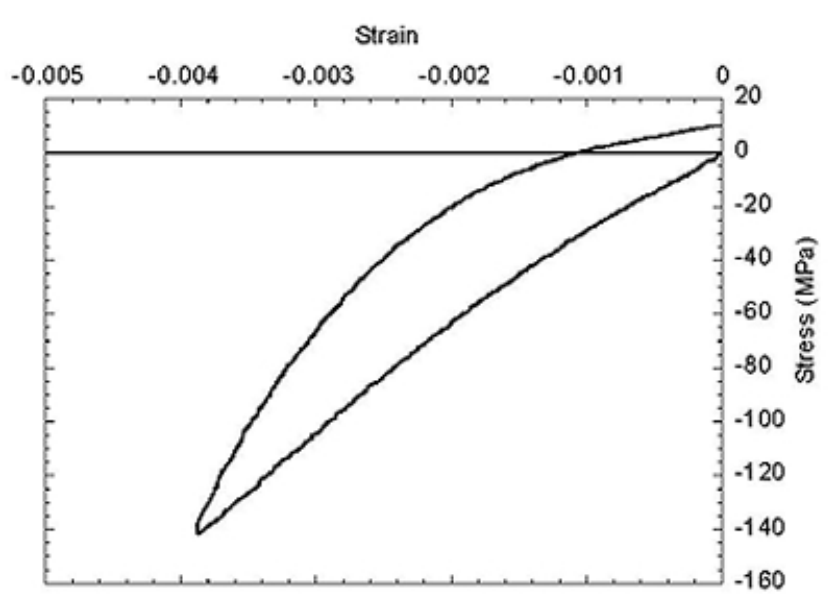

Figure 2. Calcium titanate TTBC ceramic tested at $600^{\circ}$ $\mathrm{C}$ showing the strain hysteresis developed during compressive loading.

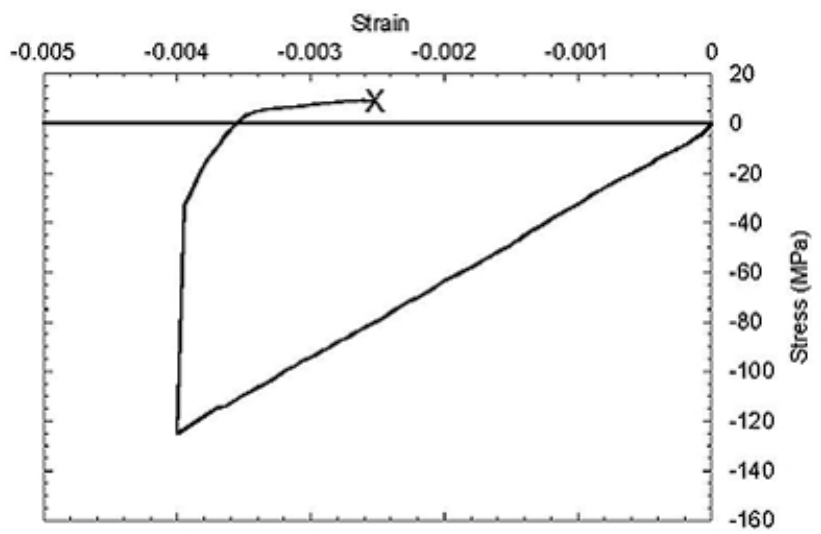

Figure 3. Calcium titanate TTBC ceramic tested at $600^{\circ}$ $\mathrm{C}$ but held at the maximum compressive load for 10 hours before unloading.

The inelastic behavior of the TTBC ceramic material also is dependent on the test temperature and loading rate. The effect of loading rate is dramatically demonstrated by holding the material at a load for a period of time. Figure 3 shows this effect for the same calcium titanate material. A similar loading rate was used as for the sample in Figure 2, but the load was held at the maximum compressive stress for 10 hours prior to unloading. This behavior is now thought to be due to the unique microstructural features of the plasma sprayed material.

The microstructure of the ceramic TTBC material reflects the spraying method used to produce the material. Ceramic powder is fed into a plasma flame, accelerated, melted and deposited onto the substrate in a successive manner similar to painting until the desired thickness of material is built up. The resulting microstructure contains pores, microcracks and areas of poor adherence between the individual "splats" produced by the molten particles impacting the surface.

The pores in the microstructure of the ceramic TTBC material, as shown in Figure 4, contribute to the low elastic modulus when compared to the bulk ceramic modulus (10 to $30 \%$ of bulk material elastic modulus). Microcracking from solidification stresses and poor adherence between the "splat" structure of the TTBC material further reduces the elastic modulus by allowing sliding between the individual "splats", Figure 5. Friction prevents complete recovery of this sliding motion and contributes to the inelastic hysteresis. The presence of small amounts of impurities such as silicon oxide creates glassy phases that have been found in the microcracks and between "splats", Figure 6. The calcium titanate material contained $0.43 \mathrm{wt} \%$ of silicon oxide. This glassy phase contributes to the creep when the TTBC material is held under load at elevated temperature. This inelastic creep at elevated temperature was also found to a lesser extent in relatively high purity zirconia TTBC materials as shown in Figure 7 . This $8 \%$ yttria stabilized zirconia contained less than $0.01 \mathrm{wt} \%$ silicon oxide.

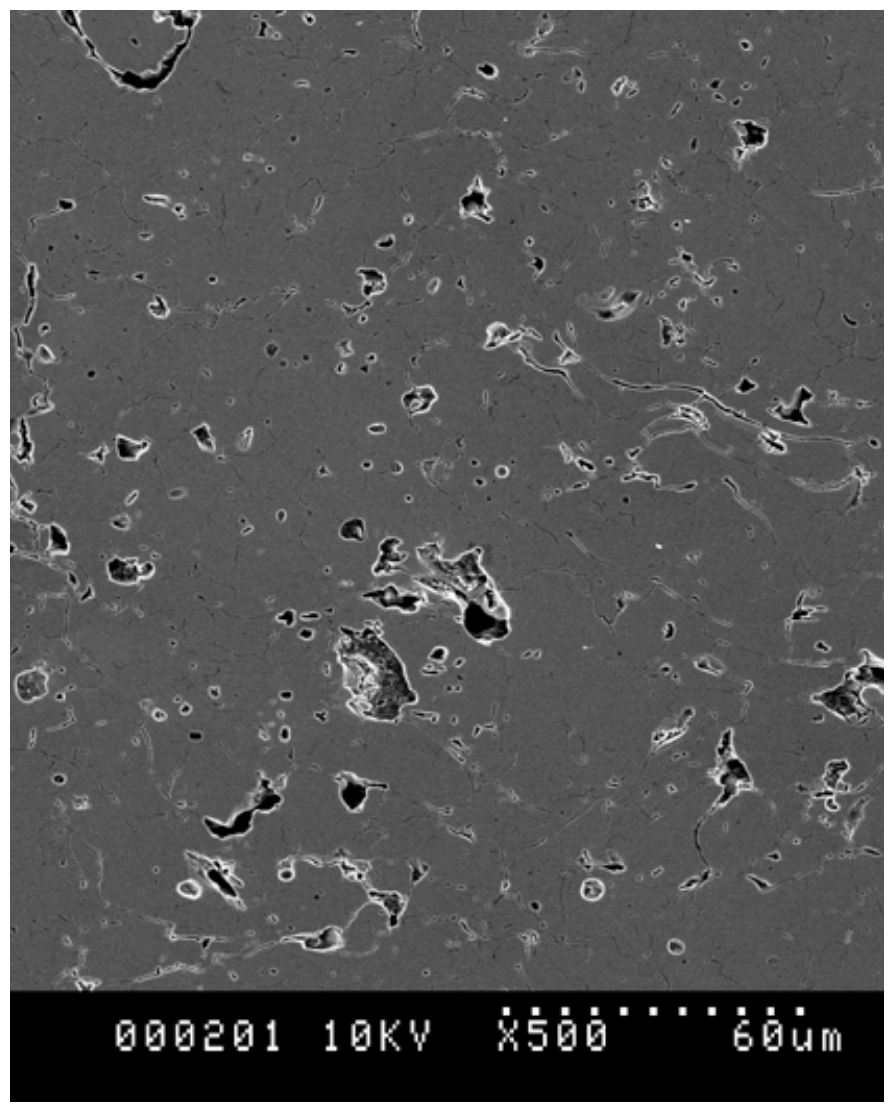

Figure 4. Typical microstructure (500X) of TTBC ceramic material showing large pores (5-20 $\mathrm{mm}$ ) created by faulty platelet (splat) stacking during processing. 


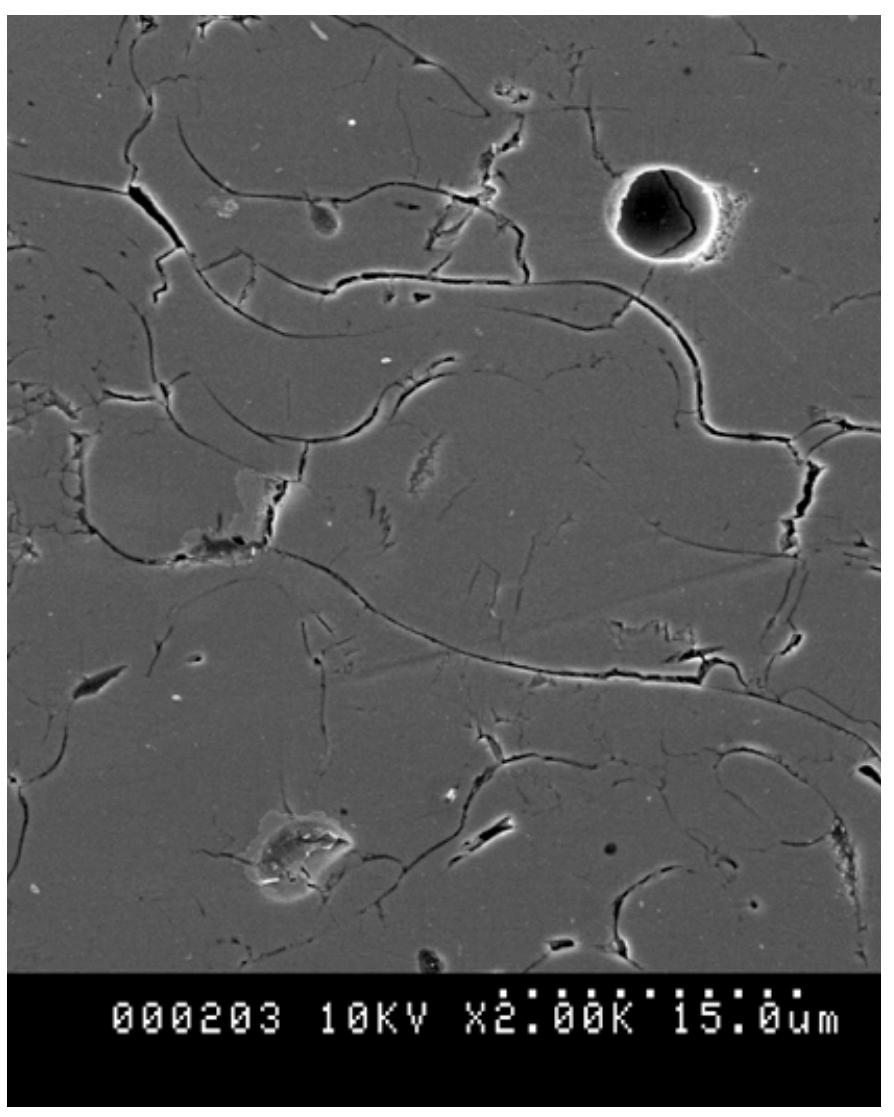

Figure 5. Higher magnification (2000X) of TTBC ceramic microstructure showing microcracks both between and within platelets (splats) occur during processing as a result of severe thermal shock.

Work is ongoing to further understand this material behavior and the resulting impact on the TTBC system durability.

\section{SEALING COATING/LOW COST MANUFACTURING}

In prior engine testing of TTBC systems, the need for a gas impermeable seal coating was recognized (Ref. 2). Sealing of the porosity is required to prevent the injected fuel from penetrating the pores of the TTBC and not burning at the optimum time required for the best efficiency.

A number of seal coating processes, ranging from penetrating dip processes to organometallic chemical vapor deposition, have been investigated. The most promising candidate seal coating process is based upon a Caterpillar patented phosphate glass material. This seal coating method not only results in a gas impermeable seal, but is also capable of being applied to the as sprayed TTBC surface and forming the final component shape and dimensions with no machining of the TTBC or seal coating. The elimination of machining as a final operation represents a major cost reduction.

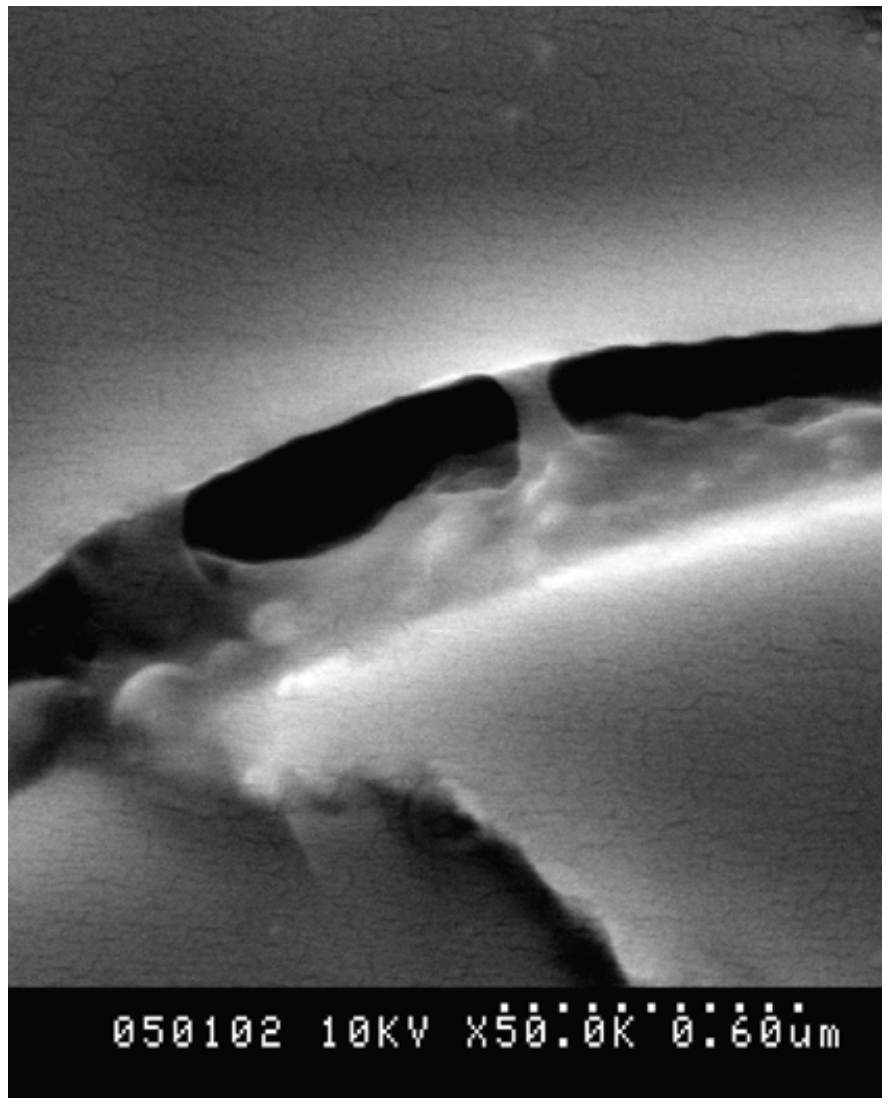

Figure 6. Glassy phase found between platelets (splats) when viewed at 20,000X magnification. The TTBC results in a significant cost reduction. The seal coating process is described below.

COMPONENT PREPARATION - The component edges, which define the extent of the TTBC, are machined prior to spraying with a relief. This provides an inset approximately equivalent to the overhang expected of the sprayed TTBC at an unmasked edge. The seal coat mold is designed to stop and pinch off seal coating flash at the sharp outside edge of the metal after the material flows completely around the sprayed surface.

MASKING - Masking of some component surfaces is required both for protection from grit blasting and coating overspray, and to help control the spray deposition at the edges.

POST-SPRAY CLEANUP - The TTBC is sprayed to a dimension $0.05 \mathrm{~mm}$ to $0.10 \mathrm{~mm}$ less than the desired final total coating thickness with seal coating. The seal coating thickness brings the component to final size and shape. 


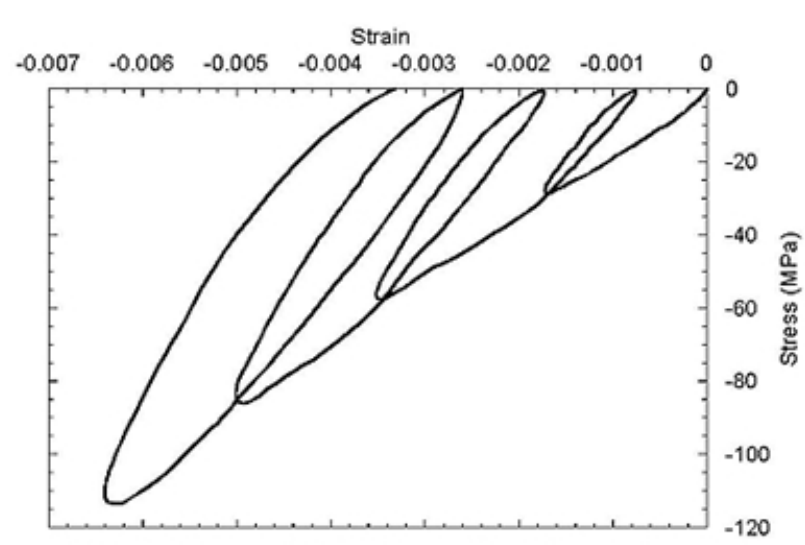

Figure 7. Elastic response of a high purity $8 \%$ yttria stabilized zirconia ceramic at $600 \times \mathrm{C}$ showing the large hysteresis build up with cycling caused by the presence of small amounts of impurities such as silicon dioxide.

SEAL COATING PREPARATION - The seal coat itself is a composite of aluminum oxide particles in a phosphate glass matrix and is designed to provide an after-formed composite ratio of about $65 \mathrm{vol} \%$ alumina to $35 \mathrm{vol} \%$ glass.

The seal coating material is prepared by tapecasting a slurry of alumina powder in an aqueous phosphate binder. The tape is cast into sheets and dried to approximately $0.5 \mathrm{~mm}$ thick, cut into patterns and inserted in the mold.

SEALING/SURFACING - The surfacing apparatus is contained within an oven and includes a chamber around the apparatus for creating a vacuum. A pneumatic press is used to apply pressure to the mold and aids in alignment of the molding fixtures.

The component is inserted into the mold with the seal coating and heated to $100^{\circ} \mathrm{C}$. A vacuum is drawn around the mold and load is applied to the mold which cause the seal coating material to take the shape of the mold. Following this, the temperature is ramped up in stages to $260^{\circ} \mathrm{C}$ where the seal coating cures.

The seal coating in the final state replicates dimensions of the mold and is ready for use with no further operations. Once cured, the seal coating is capable of resisting temperatures up to $1200^{\circ}$ with no changes in properties. The seal coating does not penetrate the pores of the TTBC but is well adhered as evident in the microstructure shown in Figure 8 . The low $260^{\circ}$ curing temperature prevents metallurgical changes to the low alloy steel and cast iron materials used for diesel engine components.

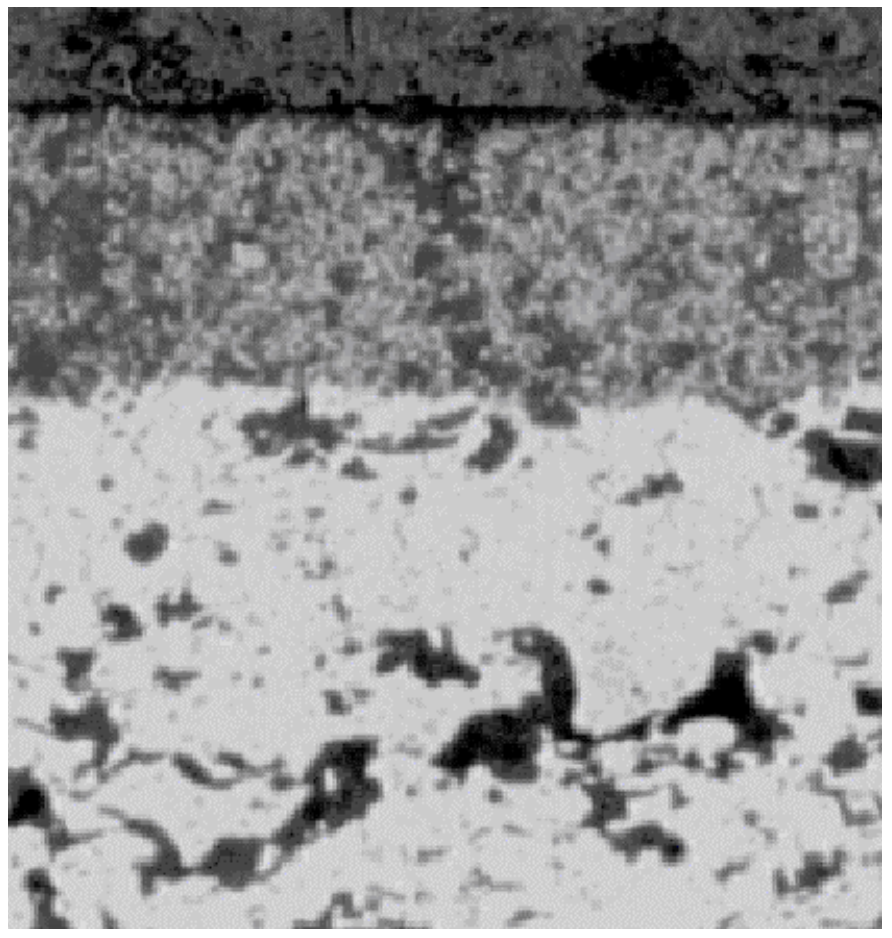

Figure 8. Seal coating microstructure showing good adherence with no penetration into the pores of the TTBC ceramic. (200X)

\section{NONDESTRUCTIVE EVALUATION (NDE) OF TTBCS}

Nondestructive evaluation is an important tool in development of TTBC systems. Current durability targets for diesel engines range from 10,000 to 30,000 hours. Engine testing is very costly. Therefore, NDE methods to determine the damage accumulated in the TTBC systems are required in order to reduce the amount of engine testing to be performed. In addition, NDE methods are needed for production of coated components.

INFRARED NDE - The technique called Time Resolved Infrared Radiometry (TRIR) is being adapted for use with thick coatings. This method, which has been developed at Johns-Hopkins and Wayne State Universities primarily for coatings of less than $1 \mathrm{~mm}$ thickness, involves heating the surface of the part to be tested and watching the evolution of surface temperature with time as the specimen cools. If a disbond exists in the coating, heat flow through the specimen will be blocked at that location and the surface temperature will be hotter than surrounding areas. Damage accumulation in the coating, such as microcrack growth, will also change the heat flow and temperature decay characteristics. For thin coatings, a flash pulse is an adequate heat source. For thicker coatings, previous work done at Caterpillar and Argonne National Laboratory (Ref. 6) suggested that a longer heating pulse was required. Thus, a high intensity arc lamp (Vortek Industries Ltd., Vancouver, B.C.) was acquired to use as a heat source. 
DESCRIPTION OF THE HEAT SOURCE - The high intensity lamp uses $50 \mathrm{~kW}$ of electrical power to produce approximately $20 \mathrm{~kW}$ of luminous power distributed primarily in the visible and UV bands. It can operate continuously for an indefinite period of time. The lamp itself requires a constant supply of argon gas and cooling water, supplied by a closed loop system. This lamp is identical to the one used in previous work (Ref. 6) except that it is of lower power and uses a different reflector system to shape the heating area. Fixturing has been built for holding the lamp head and test samples. Movement of the test samples from the lamp to an infrared detector is accomplished with a pneumatic slide.

CHARACTERIZATION OF THE HEAT SOURCE - A uniform heat flux incident on the test specimen is a requirement for maximum material characterization capability. This reduces lateral heat flow in the part and makes interpretation of the infrared image easier. Flux profiles have been acquired at a series of distances below the end reflectors of the lamp using a water-cooled calorimeter. The maximum flux was estimated to be 52 $\mathrm{W} / \mathrm{cm}^{2}$ with a minimum of $25 \mathrm{~W} / \mathrm{cm}^{2}$. This maximum is somewhat lower than the $70 \mathrm{~W} / \mathrm{cm}^{2}$ achieved with the lamp used in previous work (Ref. 6). Better uniformity of the heat flux over areas large enough for component inspection will require redesign of the reflectors used.

SYSTEM INTEGRATION AND CONTROL - The infrared NDE measurement system is similar to the one described in reference 6 and consists of the lamp, an infrared camera (3-12 micron passband), and a computer with a frame-grabber card. These devices are computer controlled in synchronization with one another in order to properly carry out the TRIR technique.

NDE MEASUREMENTS - Previous use of TRIR to inspect TTBCs as thick as $3.6 \mathrm{~mm}$ showed that artificial disbonds with a lateral dimension on the order of the defect depth within the coating could be detected using an incident flux of $70 \mathrm{~W} / \mathrm{cm}^{2}$ (Ref. 6). In order to establish sensitivity versus depth results for the current measurement system, test specimens with seeded defects of various sizes and depths have been prepared. Preliminary TRIR measurements have been made and are currently being analyzed.

\section{CONCLUSION}

The development of TTBCs will be aided by the understanding being gained about the materials' mechanical behavior. New seal coating technology that not only provides a gas impermeable seal but also allows net shape forming of the TTBC system provides an attractive, low cost method to produce TTBC components. The development of new NDE techniques will allow for the rapid development of TTBC systems.

\section{ACKNOWLEDGMENTS}

This work has been supported by Department of Energy funding through the Office of Transportation Technologies.

\section{REFERENCES}

1. M. B. Beardsley and H. J. Larson; "Thick Thermal Barrier Coatings for Diesel Components." DOE/ NASA/0332-1, NASA CR-190759, August 1992.

2. G. L. Waltz;" Development of High Temperature InCylinder Components and Tribological Systems for Advanced Diesel Engines," Proc. Of the Annual Automotive Technology Development Contractors' Coordination Meeting, SAE P-289, 1994.

3. R. C. Brink, "Material Property Evaluation of Thick Thermal Barrier Coating Systems," 89-ICD-13, The American Society of Mechanical Engineers, 1989.

4. K. F. Wesling, D. F. Socie, and M. B. Beardsley, "Fatigue of Thick Thermal Barrier Coatings," J. Am. Ceram. Soc., 77 [7], pp 1863-1868, 1994.

5. E. F. Rejda, D. F. Socie, and M. B. Beardsley, "Fatigue Behavior of a Plasma-Sprayed 8\% Y2O3ZrO2 Thermal Barrier Coating," Fatigue Fract. Engng. Mater. Struct. Vol. 20, No. 7, pp. 1043-1050, 1997

6. P. G. Happoldt, W. A. Ellingson, T. Gardiner, and J. Krueger; "Defect Detection in Multi-Layered, Plasma Sprayed Zirconia by Time Resolved Infrared Radiometry: A Comparison between Analytical and Experimental Methods." Proc. Of Thermosense XVI: An International Conference on Thermal Sensing and Imaging Diagnostic Applications, J. R. Snell, Jr., ed. SPIE Vol. 2245, pp. 210-219, 1994. 